\title{
Hanseníase: aspectos da evolução do diagnóstico, tratamento e controle
}

\author{
Leprosy: evolution aspects of its \\ diagnosis, treatment and control
}

Ana Zoé Schilling da Cunha 1

\begin{abstract}
This article describes, historically, evolution aspects of Leprosy diagnosis, treatment and control from antiquity ( 300 years b.C. until the 18th century). I t ranges from its appearance in Europe to its institutionalization, depicting the scenery in which the disease occured, the dissemination conditions, the difficulties and attempts to treat and control it, the involvement and interference of Christianism, the concern on the side of health professionals vis-à-vis the few positive results regarding its healing (from the applying of mud, blood and herb patches to the extraction of nodules and bleeding, culminating with the isolation of theill in leprosaries). Furthermore, the article highlights the decrease in the number of cases as a response to isolation in this way promoting the reduction of theillness in Brazil, arousing the attention of authorities and medical professionals as well as enforcing control policies, estipulated by $\mathrm{O}$ swaldo $\mathrm{Cruz}$, by the government representatives.
\end{abstract}

Key words Leprosy, History, Control measures

\footnotetext{
1 Departamento de

Enfermagem e Odontologia,

Universidade de

Santa Cruz do Sul.

Av. Independência 2293,

bloco 2, sala 201,

96815-900, Santa Cruz

do Sul RS.

anazoe@viavale.com.br
}

Resumo 0 trabalho descreve historicamente aspectos da evolução do diagnóstico, tratamento e controle da hanseníase na Antiguidade (300 anos a.C. até o século 18). Aborda desde o seu aparecimento na Europa até a sua institucionalização, apresentando o cenário onde ela se apresentava, as condi ções de disseminação, as dificuldades e tentativas de tratamento e controle, o envolvimento e as interferências do cristianismo, a preocupação dos profissionais da área da saúde diante dos poucos resultados em relação aos tratamentos adotados, que compreendiam desde a aplicação de cataplasmas de lama, sangue e ervas, até a extirpação dos nódulos e sangrias, culminando com o isolamento dos doentes em leprosários. Além disso, evidencia a diminuição do número de casos como resposta ao isolamento, dando início ao fim da epidemia e desaparecendo em alguns países. Aborda também as ações de controle e tratamento da doença no Brasil ea (des) preocupação das autoridades e profissionais médicos atéa inclusão de ações e normas de controle pelo poder público instituídas por Oswaldo Cruz. Palavras-chave Hanseníase, $\mathrm{H}$ istória, M edidas de controle 
Apesar do avanço das investigações, a origem da hanseníase é, ainda, um ponto obscuro para os pesquisadores. Existem poucos registros, re ferências e discussões sobre o aparecimento da doença, o que torna difícil uma abordagem mais precisa sobre o tema. Assim, pretendemos trazer os principais registros encontrados sobre 0 diagnóstico, tratamento e controle da hanseníase desde a Antiguidade.

$\mathrm{Na}$ A lexandria, 300 anos antes de Cristo, 0 mais famoso centro de estudos de medicina da Antiguidade, já se estudava a chamada “Elephantíasis", que, por muito tempo, foi confundida com a hanseníase e tratada como tal (Koelbing, 1972).*

As primeiras referências confirmadas, no entanto, apenas descrições da doença, foram encontradas na Índia e no Egito, datadas do século 7 a. C. (Frohn, 1933). Sabe-se ainda que, naépoca em que Cristo viveu, conforme citação bíblica, havia casos de hanseníase. No Antigo Testamento, em Levítico, capítulo 13, encontra-se toda uma orientação sobre a doença, seus sinais para identificação e cuidados em relação aos doentes, mas dificilmente se pode comprovar que se tratava de hanseníase. É possível que se tratasse de manchas dermatológicas de outra etiologia, ou, como observa Garmus: Os casos aqui elencados (na Bíblia), sob o termo genérico "lepra", incluem também simples infecções da pele, ou até manchas na roupa ou em edifícios. A lepra, como outras doenças, éalgo de anormal, e por isso ameaçador, que se opõe à saúde normal (Garmus, 1983) .

Os sacerdotes tinham a missão de diagnosticar e tratar a doença, visto que se relacionava com uma fraqueza oriunda de pecados e devia ser combatida através de sacrifícios, purificações e rituais que incluíam desde a queima de objetos pessoais até o contato direto do doente com o que se julgava puro, assim como um pássaro, a manjerona, a água ou a madeira de cedro (Chuoraqui, 1978).

Quanto à I dade M édia, o que se pensava e o que se sabia da hanseníase pode ser encontrado apenas nas informações dos manuscritos deixados pelos médicos da época. Além desses manuscritos, a arte e a literatura também contribuíram para a identificação da doença. Esses médicos afirmavam que o maior problema, com relação ao número de casos, localizava-se realmente no Egito (Frohn, 1933).

\footnotetext{
* Todas a traduções das obras em alemão foram feitas pela autora.
}

Contudo, Koelbing contesta esta informação e diz que: A lepra do antigo Egito, sobre a qual temos conhecimentos, não pode ser a mesma que a da atualidade; enem a Lepra do Antigo Testamento pode ser identificada com a nossa (Koelbing, 1972).

Segundo seu ponto de vista, a doença era confundida com outras doenças de pele existentes naquela época, assim como a elefantíase, a sífilis e as demais dermatoses.

$\mathrm{N}$ a verdade, até 0 século 14, o nome lepra tanto significava lesões provocadas por queimaduras, escamações, escabiose, câncer de pele, lupus, escarlatina, eczemas, sífilis, quanto lepra verdadeira.

Outros autores como Frohn (1933), Virchow (1860) e Hansen (1897) defendem a teoria de que a hanseníase já existia na Europa na época da introdução do cristianismo eque se tornou endêmica na Idade M édia entre quase todos os povos conhecidos.

$\mathrm{Na}$ visão dos medievais, as principais causas da disseminação da doença eram o contágio, a hereditariedade, o clima e a alimentação inadequada. Portanto, a hanseníase teria se tornado endêmica devido a associações de fatores como as más condições de higiene, alimentação e moradia. Esses fatores tinham origem no rápido crescimento da população e sua concentração no confinado espaço das cidades medievais, favorecendo a promiscuidade e 0 aparecimento e desenvolvimento de várias doenças, inclusive da hanseníase (D'H aucourt, 1994).

Não se pode precisar como eram as condições sanitárias na I dade M édia, porém se sabe que a expectativa de vida situava-se em torno de trinta anos e a mortalidade infantil era bastante alta. Esses dados estavam aliados à subnutrição e penúria, condições em que as epidemias se disseminavam, assim como pensa D'H aucourt: As doenças na Idade M édia eram mais ou menos as mesmas que as nossas: mas a lepra ea varíola, importadas no tempo das Cruzadas, eram, na époCa, de extrema virulência ( $D^{\prime} H$ aucourt, 1994).

0 movimento das Cruzadas e dos peregrinos é também considerado fator de disseminação da hanseníase na Europa medieval (Rosen, 1994). M uitos cruzados encontravam-se infectados pela doença, ou por aquilo que, naquela época, era considerado como hanseníase. Frohn (1933) ressalta que as Cruzadas se estenderam e permaneceram décadas no Oriente M édio, que na época estava infestado pela doença. Ao retornarem às suas casas, certamente os cruzados teriam levado a hanseníase até o mais re- 
moto povoado, contribuindo, desta forma, para a disseminação da doença.

Para Schipperges (1985), uma das principais causas do aumento do número de casos de hanseníase na Europa, nessa época, foi o atraso da medicina. Os médicos medievais eram incapazes de distinguir a hanseníase de outras doenças dermatológicas, chegando a classificá-la de duas formas, a lepra verdadeira e a lepra falsa.

Isto pode explicar a freqüência com que a cura espontânea era mencionada. Alguns autores descrevem a questão da cura espontânea, vista pelos médicos da época como sendo conseqüência da melhoria nas condições de higiene e dos esclarecimentos sobre a sua importância. Esses médicos negavam que a transmissibilidade pudesse se dar através das migrações ou do deslocamento de soldados, comerciantes e povoadores, ou ainda pelas Cruzadas ( $\mathrm{H}$ echt, 1982; Schadewaldt, 1973; Varron, 1955).

A possibilidade de contágio também pode ter sido muito maior nesse período, porque se sabe que, onde não existe ou quase não existe a doença, ela se dissemina de forma mais acelerada, configurando-se, na maioria das vezes, uma epidemia (Frohn, 1933).

Frohn (1933) afirma que, entre 1098 e 1179 d. C., Santo Hildegardo, um abade alemão, com grande senso de observação e com conhecimentos médicos, foi o primeiro a escrever sobre as formas diferenciadas da hanseníase, bem como sobre a adoção de um tratamento sistemático para a doença. Suas anotações se referiam a um tipo de hanseníase "ulcerosa", uma "rubra" e outra "alba" e diziam ainda que a doença do tipo "rubra" se manifestava em indivíduos coléricos, com vícios de embriaguez e gula. Já os tipos de hanseníase "alba" "ulcerosa" eram mais comuns em libidinosos e, como esses vícios dificilmente podiam ser controlados, a doença tardaria a evoluir para a cura.

De um modo geral, o doente nessa época era considerado pecador e, como comenta Schmitt e parafraseando uma concepção corrente do período, "a lepra também éa prova corporal do pecado: a corrupção da carne manifesta a da alma" (Schmitt, 1990).

Além da deformidade física, característica própria da doença, a falta de informações sobre o seu modo de transmissão e controle ou cura e o medo da exclusão social, que acompanhava os hansenianos nessa época, contribuíram, certamente, para que a hanseníase se tornasse uma doença temida nas populações medievais.
Nas cidades acometidas pela epidemia, qualquer pessoa ou coisa podia ser temida, já que a doença permanecia e as medidas profiláticas não surtiam o efeito desejado, restando, nesses casos, acreditar na vontade divina. Além disso, a relação divina com as calamidades, flagelos e doenças era um fato aceitável pela grande maioria: "É um flagelo da ira de Deus..." (A. Paré, citado por Delumeau, 1989).

Os medievais acreditavam na existência de seres misteriosos que habitavam os céus e que provocavam as tempestades, a loucura e as doenças. Portanto, convinha tratar com prudência os que eram responsáveis por sua saúde ou doença, prosperidade ou miséria. Muitos "santos", que também habitavam os céus, eram invocados a proteger as pessoas das diversas doenças, que, por sua vez, recebiam nomes de santos. Assim, a peste bubônica recebeu o nome de "mal de São Roque ou de São Sebastião"; a gangrena era chamada de "fogo de Santo Antônio" e a hanseníase de "mal de São Lázaro".

Santo Hildegardo, por sua vez, prescrevia tratamentos para a doença, utilizan do pomadas e longos banhos de suor por vários dias, banhos em sangue de cavalo e emplastros de terra e sangue. 0 sangue, fator de força e saúde, era amplamente utilizado no tratamento da hanseníase. Hildegardo confiava muito em suas prescrições e dizia que " $O$ doente ficará saudável ou Deus não permitirá a sua cura" (Frohn, 1933).

0 grande mérito de Hildegardo, no entanto, foi ter diferenciado a hanseníase de outras patologias como a escabiose, descamações e ulcerações dermatológicas de outra etiologia, possibilitando, mais tarde, também o diagnóstico diferencial da doença em relação ao escorbuto e à sífilis.

Nos autores medievais examinados, se percebe a parcialidadee a imperfeição na descrição da hanseníase, seus sintomas, etiologia e transmissibilidade. Na bibliografia sobre 0 assunto, aparece sempre a repetição de informações, mostrando claramente a influência de Galleno eAvicena.

Essas informações acrescentaram muito pouco ao que já se sabia sobre a doença. Além disso, aos médicos medievais só interessava a identificação da doença para depois encaminhar o doente para longe da cidade, para isolamento. 0 tratamento não trazia resultados animadores e essa situação perdurou ainda por vários séculos.

U ma importante complementação às descrições médicas dessa época pode ser encontra- 
da na literatura e na arte. A partir de quadros, pinturas e esculturas da Idade M édia, é possível recuperar e construir a completa sintomatologia da hanseníase. Sinais como nódulos, mutilações, mão-em-garra, queda do cabelo, falam claramente da doença. Ou, como pensava Virchow: D esta forma, as representações da lepra através da arte al cançam um grande significado, pois elas nos mostram claramente que 0 que aterrorizava nossos antepassados era verdadeiramente lepra (Virchow, 1860).

Sabe-se hoje que o bacilo, uma vez desenvolvida a doença, aloja-se nos nervos periféricos, provocando manchas e nódulos, principalmente no rosto, ulcerações na planta do pé e nas mãos, perda de pelos, inclusive os da sobrancelha e dos cílios, insensibilidade das extremidades, entre outros sintomas.

0 interesse pela hanseníase, sua etiologia e tratamento, começou a se evidenciar na Europa a partir do século 17, quando foram construídos os primeiros leprosários, que eram pequenos hospitais ou casas para hansenianos, geralmente sob responsabilidade de religiosos.

A esse respeito, Virchow (1860) explica que os leprosários espalham-se com a cultura da I greja e dos mosteiros, e essa cultura era, naque le tempo, essencialmente cristã. M as, com isso multiplica-se não só o número de casas de leprosos, mas também os hospitais, hospedarias e pensões para miseráveis. E como não se pode negar que doença e pobreza estão relacionadas com o desenvolvimento da cristandade na Europa medieval, também não se pode separar o crescimento da lepra do desenvolvimento da cristandade: 0 pobre torna-se um eleito de Deus, a imagem viva de Cristo, voluntariamente encarnado numa natureza pobre (Bonnassie, 1985).

$\mathrm{Na}$ verdade, o primeiro leprosário da Europa foi construído em St. Oyen (hojeSt. Claude), na França, no ano de 460 d. C., e depois, somente na metade do século 7o foi construído o de M etz, na então Alemanha, e o de Verdun, na França. Eram edificações que abrigavam até 12 pessoas, construídas do lado de fora das cidades e acompanhadas de uma capela e um cemitério.

Existem descrições sobre a forma como eram acomodados os doentes nesses leprosários me dievais: dentro das habitações, cada doente tinha direito a uma cama, um baú ou arca para guardar seus pertences e um lugar para acender sua vela. Conforme estatutos, os doentes tinham direito a receber a visita do médico pelo menos uma vez ao ano, porém alguns chegaram a ficar até onze anos sem uma visita médica (Faes, 1966).
A benemerência da Igreja a tornava inseparável dos leprosários. $\mathrm{Na}$ Espanha, a administração das casas para hansenianos era responsabilidade da I greja, assim como o bem-estar dos doentes. Em Astúrias, os leprosários sobre viviam com doações de doentes e de senhores, além de esmolas fixas doadas por entidades ou pessoas. A mendicância era praticada por quase todos os hansenianos na época (Faes, 1966).

M ollat afirma que: ...já em meados do século XIII, existiam 19 mil leprosários na cristandade ocidental; não havia povoado que não possuísse um, e, nas cercanias das grandes cidades, eles eram numerosos (M ollat, 1989).

Para ingressar nos leprosários, os doentes precisavam de uma autorização da I greja e de um "atestado médico" que comprovasse a doença, além de fazer uma doação de todos os seus bens e rendas ao hospital. Faes transcreve o conteúdo de um certificado médico expedido por um cirurgião em Astúrias, no ano de 1590: Digo yo Pedro de Hortega, cirurjano, vecino de $M$ ordonedo que, visitado, mirado, apal pado e tentado las partes necessárias de la carne de M aria, hija de Lope Gonçales, vecino de San Cristobal, para el conocimiento de su enfermedad y mal. Y despues de bien bista y picandola y travandola con las erramientas abtas a ello, e visto su poco dolor y sentimiento de sus carnes y por la color dellas y con la demás información que della e savido, la dicha M aria tiene una de las espécies de la ordem del Sr. San Laçaro, no confirmada ba en rastro berdadero della y ansi me parece se pue de acojer en la dicha ordem y tenerse por ella. Y este es mi parecer salbo eror. En M ondonedo a binte e quatro de abril 1590 anos (Faes, 1966).

Os diagnósticos também podiam conter os seguintes enunciados: "Está leproso do mal que dizem ser do Sr. São Lázaro e é servir a D eus acolhê-lo na dita ordem" ou "M al contagioso que se pega", ou ainda "É da ordem do Sr. São Lázaro, deve-se separá-lo dos que estão sãos", e também "Tem uma das quatro espécies do Sr. São Lázaro que é lepra", ou "É lepra, enfermidade incurável, contagiosa, que se pega" e"M anifestos princípios de lepra" (Faes, 1966).

0 isolamento dos hansenianos se deu também por questões biológicas relacionadas à própria doença, para a qual, na época, se desconhecia tratamento e estava sem controle. Fato é que a hanseníase começou a diminuir consideravelmente no $O$ cidente, sem contudo desaparecer, a partir do século 14.

Após o III Concílio de Latrão (1179), o isolamento passou a ser mais intenso e os doentes 
deviam estar identificados como hansenianos para poderem transitar, eventualmente, pelas cidades. Le Goff, comentando sobre a marginalização desses doentes, descreve: 0 || Concílio de Latrão, de 1179, autorizando a construção de capelas e cemitérios no interior das leprosarias, contribuiu para fazer delas outros tantos mundos fechados, de onde os gafos só podiam sair agitando matracas para que as pessoas deles se afastassem... (Le Goff, 1984).

Para to dos os hansenianos estava determinado o uso de vestimentas que tornassem possível seu imediato reconhecimento. Essa vestimenta compunha-se normalmente de um manto, um chapéu de abas largas e bermudões de cor escura, e, na túnica, trazia bordada a figura de São Lázaro. U savam luvas e carregavam na mão, ou preso a um cordão junto ao corpo, um corno ou uma matraca de madeira (Frohn, 1933).

Durante os séculos 18 e 19, quase toda a Europa adotava o isolamento como tratamento para os hansenianos e constatava uma lenta e gradativa diminuição no número de doentes. Essa diminuição no número de casos pode ter ocorrido pela evolução normal da doença e principalmente pelo isolamento de doentes, o que dificultava a transmissão.

Na Conferência sobre a Lepra, realizada em Berlim no ano de 1897, $\mathrm{H}$ ansen fez recomendações sobre a conduta para com os doentes, ressaltando a importância do isolamento destes. Ele afirmava que: 1) 0 isolamento dos doentes em sua própria casa, contribuirá para um combate mais eficaz à doença. 2) O nde existem muitos pobres hansenianos, o isolamento feito apenas em casa não será suficiente. N estes casos, o governo terá de tomar providências e isolá-los, assim como responsabilizar-se pelo cuidado e tratamento destes. 3) Cada caso dever ser examinado individualmente e então se decidir pelo isolamento facultativo ou obrigatório (Hansen, 1897).

Na tentativa de minimizar o sofrimento dos hansenianos, os europeus buscavam os mais diversificados tratamentos, mesmo antes da descoberta da doença ou de medicamentos específicos. É possível que os médicos na Antigüidade, suspeitando da incurabilidade da hanseníase, procurassem apenas aliviar os sintomas, sem, contudo, buscar a sua causa, como bem nos ilustra uma passagem de Gordônio, datada de 1697, citada por Faes: na lepra confirmada ou verdadeira, não se deveria intrometer-se, a não ser para prolongar a vida, e que o físico prediga (Faes, 1966). Propunha-se, portanto, uma posição passiva frente à doença, sem interferência na resposta do próprio organismo e, também, sem uma busca de soluções para os problemas que se apresentavam em relação ao diagnóstico e tratamento.

0 alívio dos sinais e sintomas apresentados pelos doentes era feito principalmente com ungüentos, pomadas e cataplasmas diretamente sobre os nódulos e ulcerações características da doença, além de banhos com diversas ervas. Para uma das formas de hanseníase, Santo Hildegardo, por exemplo - a forma de hanseníase considerada por ele "incurável", a qual deve corresponder à verdadeira - , recomendava banhos de terra (lama) e sangue de menstruação, tanto quanto fosse possível obter.

$\mathrm{Na}$ Espanha, Gordônio, citado por Faes (1966), registrou o uso de sangrias, banhos quentes, ingestão de caldo de carne de cobra e até a extirpação dos nódulos. A alimentação, de um modo geral, não representava fato importante no tratamento, mesmo porque a escassez de alimentos era evidente na época, predominando o milho, leite, ovos, castanhas, pouca carne e nenhuma verdura. Em relação à alta do tratamento, $90 \%$ eram por falecimento, porém, as lepras verdadeiras não recebiam alta. As demais eram dadas por cura quando o médico atestasse durante a visita ao leprosário.

Com relação ao diagnóstico, tratamento e controle da hanseníase no Brasil, médicos e estudiosos no assunto encontravam-se em permanentes pesquisas e suas descobertas contribuíram para o avanço da medicina no que diz respeito à doença. Em 1831, o médico Joaquim Cândido Soares de M eirelles apresentou em Paris um quadro comparativo entre a Elephantíasis dos gregos e dos árabes (filariose) e a hanseníase. A diferença fundamental apontada pelo médico se referia à forma e aspecto das manchas apresentadas pel os doentes: ....Cada um destes si ntomas não se observa nas duas el ephantíasis: depois de se terem destacado da superfície do corpo largas escamas leprosas ou depois de terem sido arrancadas com esforço, essas escamas não tardarão a se reproduzir. Elas podem oferecer no espaço de alguns meses ou anos um número mais ou menos considerável de descamações sucessivas. Ora, nós não notamos cousa alguma semeIhante, nem na elephantíasis dos gregos nem na dos árabes. Se estas três moléstias têm sido sempre confundidas é porque a mai or parte das descrições da lepra publicadas até o presente são inexatas, falsas ou ininteligíveis (M eirelles, 1831).

Mais tarde, a questão da sensibilidade periférica nos hansenianos foi descrita por Cândi- 
do de forma detalhada, contribuindo dessa forma para um diagnóstico diferencial com várias outras doenças que também foram confundidas com hanseníase na Antigüidade, como a sífilis e outras dermatoses: Pequenas manchas elípticas, ou irregulares, trigueiras, mais ou menos numerosas, aparecem no antebraço, região cervical, membros inferiores, tórax, etc., uma abstração completa da sensibilidade cutânea, quase sempre no terço inferior da face anterior do antebraço. M anchas vulgarmente chamadas de "panos" desaparecem e voltam conforme a alimentação, exposição ao sol, etc. Esta insensibilidade é tal que o doente corta-se com um canivete, aplica um ferro em brasas, cauteriza, sem a menor consciência. Esta insensibilidade se circunscreve, de sorte que é abaixo, acima, lateralmente. Fora, a sensibilidade é perfeita (Cândido, 1845).

No Brasil, a terapêutica empregada para todos os tipos de doenças existentes, desde a época da colonização, era baseada em plantas medicinais, com forte influência da medicina indígena. Depois, acrescentaram-se as influências da medicina usada pelos jesuítas e africanos, quetambém se utilizavam de plantas nativas em larga escala. Os portugueses e, de um modo ge ral, os europeus, introduziram um pequeno número de medicamentos importados que compunham a "caixa de botica", porém, a quantidade era extremamente limitada e a falta de medicamentos passou a ser um grande empecilho para a prática da medicina européia em terras coIoniais (Santos Filho, 1960).

Assim, a medicina no Brasil, desde o começo da colonização até o início do século 19 , constituiu-se a partir da fusão de várias formas de medicina, inclusive para o caso da hanseníase. Muitas foram as tentativas de cura da doença através das plantas medicinais, banhos com águas termais, banhos de lama, sangrias, choques elétricos, alimentação específica e até picadas de cobras.

As cobras sempre exerceram papel importante na tentativa de cura da doença, desde antigos "estudos" feitos ainda por Galeno. Da Europa chegavam notícias de tratamentos feitos com a carne e o veneno delas. Aqui, porém, as opiniões dos médicos brasileiros acerca do assunto divergiam radicalmente. Cândido (1845) prescrevia a ingestão de veneno de cobra em quantidades diluídas ( $1 / 18$ de gota) para ser misturado a uma mucilagem, variando conforme a necessidade. Justificava a prescrição alegando que as pessoas picadas por cobra "vertem sangue pelos pulmões, gengiva, reto, bexiga, uretra etc. e isto supõe a liquefação do sangue" (Cândido, 1845).

Além das sangrias, que eram feitas a cada três ou quatro semanas, ou ainda conforme a necessidade, os banhos diários e prolongados também eram recomendados. Esses banhos eram feitos por imersão, em águas tépidas e acrescidas de sabão, usando-se uma esponja para acelerar a descamação. Depois do banho, sempre se aplicavam al gumas pomadas ou ungüentos feitos de plantas, como o óleo de amêndoas.

0 galvanismo também foi usado na tentativa da cura da hanseníase, apesar de não encontrar muita aceitação e ter sido abandonado por não demonstrar resultados. Esse método consistia na aplicação de banhos galvânicos em banhei ras isoladas, com água tépida e levemente acidulada, onde o paciente recebia uma corrente galvânica por uma pilha monitorada, com um de seus pólos dirigido para a coluna cervical do doente, e o outro em contato com a água. A justificativa para tal procedimento estava no fato de que o método tornava o sangue menos coagulável e o paciente apresentava melhoras, restabelecendo sua sensibilidade periférica. Esse método, porém, não trouxe os benefícios esperados, conforme comenta Cândido (1845).

A aplicação da resina de caju foi outra tentativa feita pelos médicos brasileiros, na intenção de minimizar os sintomas apresentados pe los hansenianos. Depois da extração, aplicavase a resina sob forma de emplastro, diretamente sobre os nódulos, permanecendo fechados por 24 horas. A resina atuava como vesicatório, provocando queimadura que depois deveria ser tratada como tal, fazendo desaparecer os nódulos (Sousa-Araújo, 1956).

Em Goiás, as águas termais de Caldas de Santa Cruz constituíam outra forma de tratamento. Recomendavam-se banhos diários com águas quentes e vapores. Depois disso, o paciente submetia-se ao cautério, feito com ferro candente diretamente sobre os nódul os e tubérculos (Sousa-Araújo, 1956).

No Pará, os pacientes submetiam-se a tratamentos com ervas laxantes como uma infusão feita com folhas de açacu (Hura brasiliensis), que provocava evacuações líquidas de até quatro vezes ao dia. Seguindo o tratamento, tomavam banhos mornos na água de casca de açacu cozida e ainda banhos de vapor que eram feitos da seguinte forma: Coloca-se uma panela grande com água e casca de assacu (sic) para ferver e estende-se uma rede logo acima desta panela onde deita-se o doente coberto por um Iençol, fa- 
zendo-se instaurar a transpiração. Esta prática era condenada pelos índios, que consideravam o assacu (sic) uma planta perigosa que provocava manchas na pele e gastroenterite (Sousa-Araújo, 1956).

Não havia no Brasil, como se vê, uma normatização quanto ao tratamento e conduta em relação aos hansenianos. Apesar da existência de um grande número de médicos pesquisadores da doença, pouco se avançava em termos de profilaxia. Desde o final do século 18 , todo 0 tratamento passou a ser executado nos "lazaretos" que proliferaram com o crescente número de casos existentes, e com a necessidade de recolher os doentes andarilhos. Configurava-se, assim, o isolamento de que se falava na Europa, porém sob forma de hospital especializado.

Esta iniciativa de construção de hospitais para hansenianos deve-se ao fato de as autoridades médicas, principalmente do Rio de Janeiro, terem se convencido de que a doença poderia ser transmitida de uma pessoa a outra e não mais ser de caráter hereditário como se pensava até então. Alguns médicos haviam se pronunciado afirmando a transmissibilidade da doença, assim conforme Lima (1898) : ....e segundo parece, essa moléstia tende a disseminarse, graças talvez à crença de que ela não étransmissível.

Até o começo do século 20, a hanseníase era endêmica na maioria das regiões brasileiras, porque se alastrava de forma progressiva e estava fora de controle. As condições de vida da população até essa época favoreceram esse quadro. Da mesma forma, o atraso da medicina colaborou para que a situação chegasse a um ponto crítico. Em 1904 entrava em vigor o Regulamento Sanitário da União, determinando que a hanseníase, além de ser uma doença de notificação compulsória, colocava os doentes sob o domínio do poder público. Conforme Gomide, o poder público: ....acionou seus mecanismos de controle e se utilizou de todas as formas possíveis para identificar, no seio da sociedade, aqueles que eram considerados prejudiciais, a fim de isolá-los (Gomide, 1991).

Enquanto isso, no final do século 19, na Europa, a hanseníase havia praticamente desaparecido: descoberto o bacilo e as suas características, os doentes foram imediatamente isolados para que a transmissão da doença não mais ocorresse. A partir de então, os rumos das pesquisas e das medidas de controle se mostraram mais eficientes, tanto na Europa quanto em outros países.
Quando a situação se mostrou fora de controle, os médicos brasileiros passaram a se interessar pela hanseníase, fazendo estudos, pesquisas e cursos no exterior, como na França e na Alemanha, trazendo mais informações sobre o tratamento e medidas de profilaxia. Concomitantemente, as autoridades médicas sofriam, por um lado, pressões da população, que clamava por medidas urgentes de combate à doença e, por outro lado, submetiam-se à morosidade, à falta de vontade política e ao desinteresse de al gumas autoridades estatais na liberação de recursos para providências simples como o isolamento dos doentes.

Os hansenianos brasileiros, tal qual ocorreu na Idade M édia européia, sobreviviam das esmolas recolhidas nas ruas ou de doações de religiosos. Isso os colocava na mesma situação social que os miseráveis, desempregados, prostitutas e criminosos. Eram tratados por alguns governantes como caso de polícia, usava-se até de violência para afugentá-los das cidades, mantendo-os por muito tempo em contato com a população mais carente e deficiente em termos de saúde, contribuindo assim para que a doença se al astrasse ainda mais.

Algumas medidas eram tomadas pelos médicos nomeados pelas autoridades da época, em relação aos cuidados com os comunicantes da doença, como, por exemplo, a de impedir o casamento entre hansenianos, retirar as crianças do meio familiar de doentes, proibir 0 aleitamento materno a crianças de mães e amas- deleite portadoras da doença, eainda tornar obrigatória a notificação de qualquer caso suspeito da hanseníase às autoridades sanitárias e criar um registro estatístico da doença no Brasil. Essas medidas governamentais foram repassadas a todas as províncias através das Inspetorias de Saúde Pública criadas desde 1890 (decreto no 169, de 18 de janeiro de 1890).

Em 1903, quando Oswaldo Cruz assumiu a então Diretoria Geral de Saúde Pública, a hanseníase passou a ter maior atenção do poder público, e fazer parte dos programas governamentais de combate às doenças transmissíveis. Isso aconteceu a partir do seu relatório feito ao ministro da Justiça e Negócios I nteriores: A propagação se faz por contágio, isto é, pelo contato imediato ou mediato com o doente, que éa única fonte. 0 contágio é lento e varia segundo a forma da moléstia... N ão se conhecem ainda as vias de penetração dos bacilos no organismo humano; supõe-se que penetrem pela mucosa nasal, por via genital e por via cutânea (Cruz, 1905). 
A partir do final do século 19, as legislações brasileiras passaram a contemplar as questões mais sérias da saúde como um problema de ordem social, que deveriam sofrer a interferência do governo para a sua resolução. Para tanto, foram criados os Consel hos, Inspetorias, Diretorias e Serviços de Saúde Pública, que tinham a incumbência de fazer recomendações, regulamentos e ordens, além de promover a vigilância sanitária e manter um serviço de notificações e de estatística.

\section{Referências bibliográficas}

Bertolli FC 1998. História da saúde pública no Brasil. 2aa ed. Ed. Ática, São Paulo.

Bíblia Sagrada 1983. N.T. M ateus. 4a ed. Vozes, Petrópolis. Bonnassie P1985. Dicionário de História M edieval. Publicação Dom Quixote, Lisboa.

Cândido JP 1845. Reflexão sobre a M orphéa. Annaes de M edicina Brasiliense 1(7):252-275.

Chuoraqui A 1978. Os homens da Bíblia. Cia. das Letras, São Paulo.

Cruz 0 1905. Relatório apresentado ao Exmo Sr. Dr. J. J. Seabra, M inistro da Justiça e N egócios Interiores. De partamento da Imprensa Nacional, Rio de Janeiro.

Delumeau J 1989. História do medo no ocidente - 13001800. Cia. das Letras, São Paulo.

D’H aucourt G 1984. A vida na Idade M édia. M artins Fontes, São Paulo.

Faes JT 1966. H ospitales de leprosos en Asturias durante las edades media y moderna. O viedo, [s.n.]

Frohn W 1933. Der aussatz im Rheinland; sein vorkommen und seine bekämpfung. Gustav Fischer, Jena.

Garmus L 1983. Bíblia Sagrada. 4a ed. Vozes, Petrópolis.

Gomide LRS 1991. Órfãos de pais vivos. A lepra e as instituições preventórias no Brasil: estigma, preconceitos e segregação. Universidade de São Paulo, São Paulo.

H ansen GA 1897. U bertragung der lepra von mensch zu mensch. Facultative oder obligartorische isolation der leprösen. In Lepra Konferenz, 1, 1897, August Hirschwald, Berlim.

Hecht I 1982. Der siechen wandel. Die aussätzigen im mittelalter und heute. Freiburg, [s.n.].

Iyda M 1993. Cem anos de saúde pública. A cidadania ne gada. Unesp, São Paulo.

Koch R 1912. Die leprakrankheit in Kreis M emel. Leipzig, [s.n.].

Koelbing H M u.a.,1972. Beiträge zur geschichte der lepra. Zurique [s.n.].

Le Goff J 1984. A civilização do ocidente medieval. v.1. Imprensa Universitária, Lisboa.

Lima JJA 1898. A lepra no Brasil. Gazeta M édica da Bahia 29(6):263-272, dez. 1897; 29(7):322-33.
M eirelles JCS 1831. Paralelo entre as duas espécies de elephantíasis e entre a lepra. Semanário da Sociedade de M edicina do Rio de Janeiro 1(26).

Mollat M 1989. Os pobres na Idade M édia. Campus, Rio de Janeiro.

Rosen G 1994. U ma história da saúde pública. Unesp, São Paulo.

Santos Filho L 1960. M edicina colonial. In H Sérgio Buarque (org.) História da civilização brasileira. DIFEL, São Paulo.

Schadewaldt H 1973. Zur Geschichte der Lepra. In B Falco. Hautarzt Berlin. Regensburg und Biermann, Berlim-H eidelberg-Nova York.

Schipperges H 1985. Der garten der gesundheit. medizin im mittelalter. Deutsches Taschenbuch, MuniqueZurique.

Schipperges H 1993. Die kranken im mittelalter. C. H. Beck, Munique

Schmitt JC 1990. A história dos marginais. In Le Goff, Jacques. A história nova. M artins Fontes, São Paulo.

Sousa-Araújo HC 1956. História da lepra no Brasil; 15001952. Departamento da Imprensa Nacional, Rio de Janeiro.

Souza-Araújo HC 1936. A lepra e as organizações antileprosas do Brasil. In M emórias do Instituto O swaldo Cruz. Departamento da Imprensa Nacional, Rio deJaneiro.

Varron AG 1955. Der angst vor krankheiten im mittelalter. CIBA, Wehr/Baden 7(74):2.462-2.466.

Virchow R 1865. Die krankheiten geschwiste. Karger, Berlim.

Virchow R 1897. Die stellung der lepra den infektionskrankheiten und die pathologisch-anatomische erfahrung. In Lepra Konferenz 1. August Hirschwald, Berlim.

Virchow R 1860. Zur geschichte des aussatzes besonders. In Deutschland nebet einer aufforderung an ärtze und geschichtsforscher. August Hirschwald, Berlim.

Artigo apresentado em 8/6/2001

Versão final apresentada em 14/11/2001

Aprovado em 8/2/2002 